\title{
Who continues to smoke while pregnant?
}

\author{
Sven Cnattingius, Gunilla Lindmark, Olav Meirik
}

\begin{abstract}
Study objective-The aim was to study changes in smoking habits during pregnancy and differences in characteristics between women who stop smoking and those who continue to smoke during pregnancy.

Design-The study was a population based prospective study. Self administered questionnaires were completed on three occasions.

Setting-The study area was Uppsala county, Sweden, in 1987.

Participants-The participants were women registered with antenatal care clinics, which included all pregnant women in the county. Ninety six percent $(n=3678)$ of all pregnant women completed the first questionnaire. Thirty two percent of these were smokers at time of conception.

Measurements and main resultsTwenty nine percent of the smokers stopped smoking at some stage of pregnancy, and the majority did so before having registered for antenatal care. Using logistic regression analysis it was found that high parity number, not living with infant's father, heavy smoking, and daily passive smoking at home were associated with significantly increased risk for continued smoking during pregnancy. High level of education and high age at onset of smoking decreased the risk.

Conclusions-In order to reduce the smoking related risks for unsuccessful pregnancy outcome, general preventive efforts in society must be combined with the development of more specialised antenatal programmes designed with consideration of the characteristics and life situation of the pregnant smoker.
\end{abstract}

University Hospital, Uppsala University, S-751 85 Uppsala Sweden:

Department of Social Medicine

$S$ Cnattingius

Department of

Obstetrics and

Gynaecology

G Lindmark

Human Reproductive

Programme, WHO,

Geneva, Switzerland

O Meirik

Correspondence to:

Dr Cnattingius

Accepted for publication May 1991
Although maternal smoking in the developed world may be regarded as the most important preventable risk factor for an unsuccessful pregnancy outcome, ${ }^{1-5}$ many women smoke during pregnancy. In studies from Canada and England, $30-40 \%$ of the pregnant population have been found to smoke in early pregnancy. ${ }^{67}$ Despite improved general knowledge of the hazards of smoking in relation to pregnancy outcome, the majority of pregnant smokers continue to smoke during pregnancy ${ }^{6}{ }^{7}$ It has also been reported that smoking during pregnancy may be associated with such characteristics as social status, level of education, level of addiction, and stress. ${ }^{6-8}$
Basic knowledge about smoking mothers is important in order to develop successful health care programmes. In the development of antismoking programmes, one also has to take into account what kind of health care system the pregnant women are offered and the attendance of the pregnant population for antenatal care.

In Sweden, the pregnant population is considered relatively homogeneous with regard to nutritional and social factors. Antenatal care is free and all women visit the antenatal clinics during pregnancy. ${ }^{9}$ About $30 \%$ of the pregnant population are smokers in early pregnancy. ${ }^{1}$ There are no data on smoking habits during pregnancy or on sociodemographic determinants of smoking during pregnancy. In order to study these issues, we conducted a prospective study, which included all pregnant women registered in antenatal care in a large urban-rural area in Sweden during one year.

\section{Methods}

The study was performed at the antenatal clinics in Uppsala county, Sweden. All women with normal pregnancies, registered before 21 completed gestational weeks during 1987, were asked to complete non-anonymous questionnaires three times during pregnancy. The first questionnaire was completed at the time of registration $(90 \%$ registered before the 14th gestational week). This questionnaire mainly included questions regarding sociodemographic background, previous obstetric history, previous and present smoking habits, and smoking habits among individuals in the immediate environment. Roughly $96 \%$ of the pregnant population completed the first questionnaire. The second and third questionnaires were completed in the middle of pregnancy (24-26th week) and in late pregnancy (34-36th week). These questionnaires mainly included questions on current smoking habits.

Multiple regression analyses were performed in order to estimate the effects of the studied independent variables on smoking habits. ${ }^{10}$ Initially, all independent variables were included in the analyses. However, in order to make the analyses as simple and illustrative as possible, the final models only included variables that were found to have a significant influence on changes in smoking habits during pregnancy. Data were computerised and the statistical analyses were made using the Statistical Analyses System (SAS). ${ }^{11} 12$

Permission to perform the study was granted by the ethics committee of Uppsala University and by the Swedish Data Inspection Board. 


\section{Results}

Ninety six percent $(n=3678)$ of women registered at the antenatal clinics in 1987 completed the first questionnaire. Thirty two percent $(n=1160)$ of the pregnant population stated when registering for antenatal care that they were daily smokers at the time of conception. Of these women, 36 had spontaneous abortions shortly after registration and 20 moved outside the county during pregnancy. Of the remaining 1104 smokers at the time of conception, $98 \%(n=1078)$ completed the second and third questionnaires.

Table I Summary of among women, smoking at time of conception, Uppsala county, Sweden, $1987(n=1078)$ subsequent smoking habits

\begin{tabular}{lrr}
\hline & $n$ & $\%$ \\
\hline Stopped smoking & 191 & 18 \\
before registration for antenatal care & 72 & 7 \\
$\begin{array}{l}\text { week } 10-24 \\
\text { week } 25-36\end{array}$ & 44 & 4 \\
$\begin{array}{l}\text { Stopped temporarily } \\
\text { Cut down cigarette consumption by }\end{array}$ & 66 & 6 \\
$\quad$ > cigarettes per day & 181 & 17 \\
Persistent smoking & 524 & 49
\end{tabular}

Table II Smoking habits during pregnancy according to maternal sociodemographic characteristics among women smoking at time of conception. Uppsala county, Sweden, $1987(n=1078)$

\begin{tabular}{|c|c|c|c|c|}
\hline & $\begin{array}{l}\text { Total } \\
n\end{array}$ & $\begin{array}{l}\text { Stopped } \\
\text { smoking } \\
\%\end{array}$ & $\begin{array}{l}\text { Stopped } \\
\text { temporarily or } \\
\text { cut down by } \\
>5 \text { cig/day } \\
\%\end{array}$ & $\begin{array}{l}\text { Persistent } \\
\text { smoking } \\
\%\end{array}$ \\
\hline \multicolumn{5}{|l|}{ Maternal age (years) } \\
\hline $15-19$ & 51 & 22 & 29 & 49 \\
\hline $20-24$ & 330 & 27 & 24 & 49 \\
\hline $25-29$ & 351 & 30 & 23 & 46 \\
\hline $30-34$ & 228 & 29 & 21 & 49 \\
\hline $35-$ & 118 & 29 & 19 & 52 \\
\hline \multicolumn{5}{|l|}{ Number of previous births } \\
\hline 0 & 493 & 36 & 30 & 34 \\
\hline 1 & 346 & 25 & 17 & 59 \\
\hline 2 & 177 & 23 & 15 & 62 \\
\hline$\geqslant 3$ & 62 & 10 & 24 & 66 \\
\hline \multicolumn{5}{|l|}{ Education (years) } \\
\hline$\leqslant 9$ & 319 & 17 & 22 & 61 \\
\hline $10-12$ & 562 & 28 & 22 & 49 \\
\hline$>12$ & 194 & 48 & 27 & 25 \\
\hline \multirow{2}{*}{\multicolumn{5}{|c|}{ Working conditions }} \\
\hline & & & & \\
\hline Presently employed & 888 & 29 & 24 & 47 \\
\hline Not presently employed & 140 & 18 & 16 & 66 \\
\hline \multirow{2}{*}{\multicolumn{5}{|c|}{ Relationship with father }} \\
\hline & & & & \\
\hline Living with father & 977 & 30 & 22 & 48 \\
\hline Not living with father & 95 & 18 & 29 & 53 \\
\hline Unknown & 6 & - & - & - \\
\hline
\end{tabular}

Table III Smoking habits during pregnancy according to previous smoking status and smoking habits in the environment. Women smoking at time of conception, Uppsala county, Sweden, $1987(n=1078)$

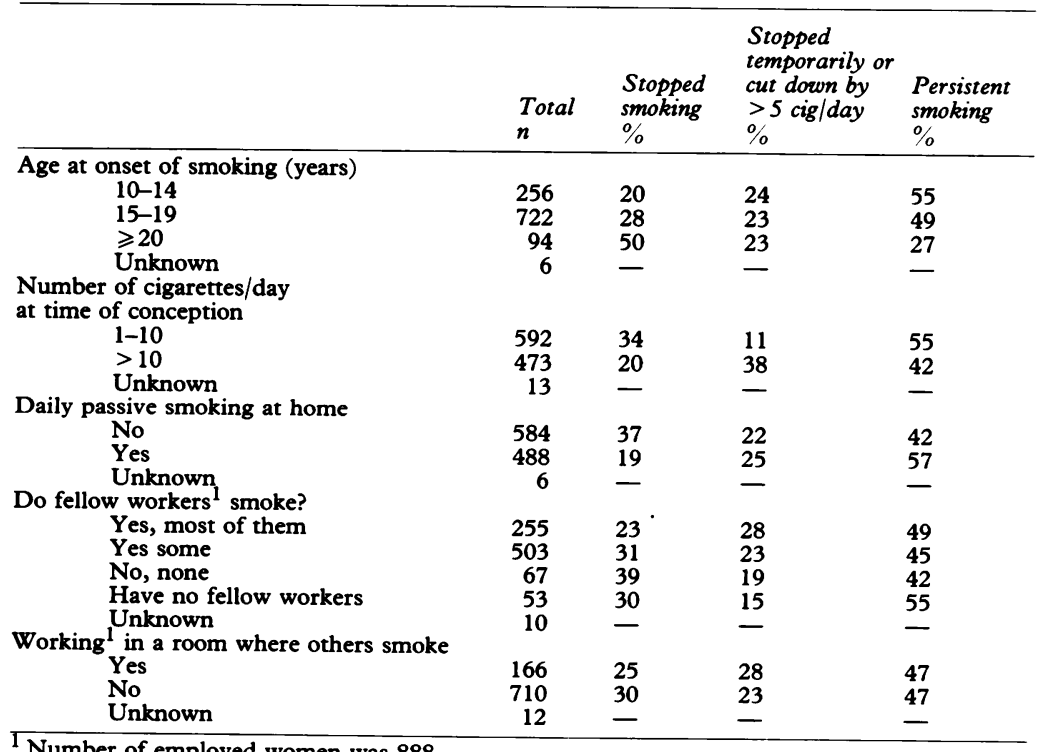

Of 1078 study subjects, $95 \%$ stated when admitted to antenatal care that they had been informed about the hazards of smoking during pregnancy. During pregnancy, this figure rose to $99 \%$.

Four percent increased their consumption by more than five cigarettes per day during pregnancy. Twenty nine percent stopped smoking during pregnancy. The majority of these women did so before being registered for antenatal care (table I). In about half of the women who smoked at time of conception there was no significant change in smoking habits during pregnancy.

Table II shows smoking habits during pregnancy according to maternal demographic and socioeconomic characteristics. Among women with at least three previous births, $66 \%$ did not change their smoking habits during pregnancy (persistent smokers), while the corresponding figure for nulliparas was $34 \%$. Other factors associated with persistent smoking were low level of education and not presently working. Parous women were also asked if they had smoked during their most recent pregnancy. Eighty three percent of parous women answered that they had smoked during the major part of that pregnancy.

In table III the women's smoking habits during pregnancy are related to previous smoking habits and to smoking habits in the woman's environment. Persistent smoking was especially prevalent among women with a low onset age of smoking and women exposed to daily passive smoking at home.

The women were also asked about the presence (or absence) of different psychosomatic symptoms, such as chest pain, back pain, insomnia, and anxiety. The prevalence of such symptoms in early pregnancy was not found to be related to smoking habits during pregnancy.

In tables II and III, the pregnant women's characteristics and smoking habits during pregnancy are presented. However, many of these variables are interrelated. For example, maternal education is, according to table II, correlated with maternal smoking habits. Educational level also correlates with other factors which may have an influence on maternal smoking habits (ie, low age of onset of smoking and daily passive smoking at home). Therefore, when studying the importance of each factor for smoking during pregnancy, such variations require a multivariate approach.

Table IV shows the adjusted relative risks of different factors on continued smoking during pregnancy. In this multivariate analysis, the term "continued smoking" was applied to those women who did not stop smoking permanently (ie, according to tables II and III, it includes persistent smokers, those who stopped temporarily only, and those who cut down the amount of smoking). As can been seen in table IV, high parity, not living with infant's father, heavy smoking, and the presence of other smokers at home were factors independently associated with increased risk for continued smoking during pregnancy. High educational level and a high age at the onset of smoking, on the other hand, decreased the risk for continued smoking. Maternal age did not significantly influence the 
Table IV Relative risk for continued smoking during pregnancy among women smoking at time of conception. The results are based on a logistic regression model of women registered at the antenatal clinics in Uppsala county, Sweden, during 1987 $(n=1045)$

\begin{tabular}{|c|c|}
\hline & $\begin{array}{l}\text { Relative risk } \\
\text { (95\% confidence } \\
\text { interval) }\end{array}$ \\
\hline \multicolumn{2}{|l|}{ Parity } \\
\hline No previous birth (reference group) & \\
\hline 1-2 previous births & $1.6(1.3-1.7)$ \\
\hline$\geqslant 3$ previous births & $1.9(1.3-2.3)$ \\
\hline \multicolumn{2}{|l|}{ Educational level } \\
\hline$\leqslant 9$ years & $1.2(1.0-1.5)$ \\
\hline $10-12$ years (reference group) & 1.0 \\
\hline$>12$ years & $0.7(0.5-0.9)$ \\
\hline \multicolumn{2}{|l|}{ Relationship with father } \\
\hline Living with father (reference group) & 1.0 \\
\hline Not living with father & $1.6(1.2-2.0)$ \\
\hline \multicolumn{2}{|l|}{ Working conditions } \\
\hline Presently employed (reference group) & 1.0 \\
\hline Not presently employed & $1.0(0.7-1.4)$ \\
\hline Student & $0.6(0.3-1.0)$ \\
\hline \multicolumn{2}{|l|}{ Age at onset of smoking } \\
\hline $10-14$ & $1.1(0.9-1.4)$ \\
\hline $15-19$ (reference group) & 1.0 \\
\hline$\geqslant 20$ & $0.6(0.4-0.9)$ \\
\hline \multicolumn{2}{|l|}{$\begin{array}{l}\text { Number of cigarettes smoked per day at } \\
\text { time of conception }\end{array}$} \\
\hline $1-10$ (reference group) & \\
\hline & $1.6(1.4-1.8)$ \\
\hline \multicolumn{2}{|l|}{ Daily passive smoking at home } \\
\hline No (reference group) & \\
\hline Yes & $1.6(1.4-1.8)$ \\
\hline
\end{tabular}

risk for continued smoking and was therefore not included in the final model.

\section{Discussion}

Due to the relatively high prevalence of smoking during pregnancy in Sweden (about 30\%), it has been estimated that smoking may account for a significant proportion of late fetal deaths and small gestational age (SGA) infants. ${ }^{13}$ However, as late fetal death is a relatively rare condition, the individual risk for this is generally low. Even though smoking increases late fetal death rate by $40 \%, 1$ smokers generally have apparently normal pregnancy outcomes. Furthermore, although the liveborn SGA infant faces increased risks for complications in the neonatal period and for neurological sequelae, ${ }^{14}$ the long term prognosis for these infants is generally good. ${ }^{15}$ Thus, despite the fact that a pregnant smoker today is practically always aware of the risks of smoking during pregnancy, she may on good grounds disagree with the health care personnel about the relevance of these risks for her individual pregnancy.

Findings from a previous investigation have suggested that parous women are more likely to smoke during pregnancy. ${ }^{16}$ These findings are borne out by this investigation. Parous smokers had generally also smoked during their most recent pregnancy. Thus, although smoking during pregnancy, these women generally have personal experiences of giving birth to one or more normally formed healthy babies, and may therefore be less motivated to change their smoking habits in connection with subsequent pregnancies.

In accordance with previous studies, ${ }^{67}$ the results obtained suggest that persistent smokers generally are less educated. However, maternal education is intimately linked to other factors which also influence smoking habits during pregnancy, and this led us to use a multivariate statistical analysis. Such an analysis is probably a very crude measure of possible reasons for continuing to smoke during pregnancy. Oakley ${ }^{8}$ has suggested that smoking during pregnancy "is self-consciously a coping strategy, and/or is an attempt to claim space and time for onself amidst the draining responsibilities of everyday life". The present study was based on three self administered questionnaires, with limited possibilities to explore such hypotheses. We found, however, that smoking during pregnancy was more prevalent among single women and women not employed, which could be in accordance with the coping strategy. No differences in psychosomatic symptoms in early pregnancy were found between persistent smokers and those who stopped smoking. In an unselected Swedish pregnant population, the influence of the coping strategy on smoking habits during pregnancy would probably be less than in the study of Oakley, in which the women examined were mainly socially disadvantaged.

When registering for antenatal care, the pregnant woman spends at least one hour with the midwife. The woman is interviewed regarding sociodemographic factors, previous obstetric history, and lifestyle factors which may have a bad influence on pregnancy outcome. The woman is offered information and advice (verbally by the midwife, as well as through booklets) as to how she can promote her infant's health. Much of this information concerns smoking during pregnancy. During the forthcoming visits for antenatal care (the mean number of visits is 13), the smoking woman is generally offered more information about the hazards of smoking as well as encouragement to stop smoking. After these visits in the "health oasis", the woman is back into the desert of reality, and at home she often meets a smoking husband. Although the association between passive smoking and pregnancy outcome today must be considered controversial, it has been suggested that passive smoking is a negative factor in pregnancy outcome. ${ }^{17} 18$ In the present study, smokers were less likely to give up the habit if others (usually the woman's partner) smoked daily at home. The partner's role in smoking cessation programmes may be very important, not only through the direct influence on pregnancy outcome by increased smoking cessation rates among pregnant women, ${ }^{6}$ but possibly also through decreased levels of side stream smoke. ${ }^{17} 18$

In the results obtained, $29 \%$ of women stopped smoking at some stage during pregnancy. This does not necessarily mean that the attributable risk was reduced by the same amount. From several studies a dose-response relationship between number of cigarettes smoked and infant's birthweight has been reported. ${ }^{513}$ In accordance with previous findings, ${ }^{6}$ we found that heavy smokers were less likely to quit smoking, but more likely to cut down on the amount smoked per day. Women strongly addicted to cigarettes may be regarded as the hard core, and sometimes a significant reduction of number of cigarettes smoked per day must be regarded as sufficient.

In the early 1960s, when the hazards of smoking were not known to the public, $97 \%$ of the Swedish smokers continued to smoke during pregnancy. ${ }^{19}$ The spreading knowledge of smoking and pregnancy outcome, which today has reached practically all pregnant women, is probably the main reason why $29 \%$ in the present study quit smoking during pregnancy. This knowledge is evidently gained mainly from sources other than antenatal care, since most mothers stopped smoking before registering for antenatal care. 
Theoretically, pregnancy (which provides one of the best of motives to stop smoking) and antenatal care (with repeated regular visits over a period of months) constitute a unique opportunity for successful smoking intervention. From other studies it has been concluded that successful smoking intervention during pregnancy requires far more than information and encouragement. ${ }^{820}$ Windsor and Orlean $s^{20}$ reviewed eight experimental studies of smoking intervention during pregnancy. The studies were performed within antenatal care, but home visits were sometimes also performed. Extensive work was devoted to these projects, but only one study managed to find differences in smoking pattern as well as in birthweight between treatment and control groups. In accordance with previous investigations, ${ }^{6-81621}$ the results of the present study suggest that the characteristics of persistent smokers differ in many ways from those of smokers who stop smoking during pregnancy. In the long run, primary preventive work in order to reduce the number of girls and young women who start smoking may be the most important. In Sweden today, 30 to $40 \%$ of women aged 16 to 24 years are daily smokers. ${ }^{22}$ Thus general preventive efforts must be combined with the development of more specialised antenatal programmes for smoking intervention designed with the consideration of the characteristics and life situation of "the persistent smoker".

We are indebted to Monika Forsling at the Department of Social Medicine, Uppsala University. The study was supported by grants from The Bank of Sweden's Tercentenary Fund and The Swedish Tobacco Company.

1 Cnattingius S, Haglund B, Meirik O. Cigarette srroking as a risk factor for late fetal and early neonatal death. $13 M \mathcal{F} 1988$;
297: $258-61$.
2 Haglund B, Cnattingius S. Cigarette smoking as a risk factor for sudden infant death syndrome. A population-based study. Am f Public Health 1990; 80: 29-32. 3 Kleinman JC, Pierre MB, Madans JH, Land GH, Schramm WF. The effects of maternal smoking on fetal and infant
mortality. Am $\mathcal{F}$ Epidemiol 1988; 127: 274-82.

mortality. Am F Epidemiol 1988; 127: 274-82.

Malloy MH, Kleinman JC, Land GH, Schramm WF. The association of maternal smoking with age and cause of infan death. Am f Epidemiol 1988; 128: 46-55.

5 Sexton $M$, Hebel $R$. A clinical trial of change in maternal smoking and its effect on birthweight. $\mathcal{F} A M A 1984 ; 251$ : 911-5.

6 Madeley RJ, Gilles PA, Power FL, Symonds EM. Nottingham mothers stop smoking project-baseline survey of smoking in pregnancy. Community Med 1989; 11 $124-30$.

7 Stewart PJ, Dunkley GC. Smoking and health care patterns among pregnant women. Can Med Assoc f 1985; 133 989-94.

8 Oakley A. Smoking in pregnancy: smokescreen or risk factor? Towards a materialist analysis. Sociol Health Illness 1989; 11: 311-35.

9 Rooth G. Better perinatal health. Lancet 1979; ii: 1170-2.

10 Schlesselman JJ. Case-control studies. Design, conduct, analyses. New York: Oxford University Press, 1982.

11 SAS Institute. SAS user's guide: basics. Version 5. Cary, SAS Institute. SAS user's guide: basics.
North Carolina: SAS Institute 1985 .

12 SAS Institute. SAS user's guide: statistics. Version 5. Cary, North Carolina: SAS Institute 1985.

13 Cnattingius $S$. Does age potentiate the smoking-related risk of fetal growth retardation? Early Hum Dev 1989; 20 203-11.

14 Sabel K-G, Olegård R, Victorin L. Remaining sequelae with modern perinatal care. Pediatrics 1976; 57: 652-8.

15 Ounstedt MK, Moar VA, Scott A. Children of deviant birthweight at the age of seven years: health, handicap, size and developmental status. Early Hum Dev 1984; 9: 323-40.

16 Waterson EJ, Murray-Lyon M. Drinking and smoking patterns amongst women attending an antenatal clinic: II. During pregnancy. Alcohol Alcoholism 1989; 24: 163-73.

17 Martin TR, Bracken MB. Association of low birthweigh and passive smoke exposure in pregnancy. $A m \mathcal{f}$ Epidemiol 1986; 124: 633-42.

18 Rubin DH, Krasilnikoff PA, Leventhal JM, Weile B, Berget A. Effect of passive smoking on birthweight. Lancet 1986; ii: $415-7$.

19 Kullander S, Källén B. A prospective study of smoking and pregnancy. Acta Obstet Gynecol Scand 1971; 50: 83-94.

pregnancy. Acta Obstet Gynecol Scand 1971; 50: 83-94.
Windsor RA and Orleans CA. Guidelines and methodological standards for smoking cessation methodological standards for smoking cessation intervention research among pregnant women: improving
the science and art. Health Educ $Q$ 1986; 13: 131-61.

21 Johnson SF, McCarter RJ, Ferencz C. Changes in alcohol cigarette and recreational drug use during pregnancy: implications for intervention. Am $\mathcal{f}$ Epidemiol 1987; 126: 695-702.

22 Rosén $M$, Waii $S$, Hanning $M$, Lindberg G, Nyström L. Smoking habits and their confounding effects among occupational groups in Sweden. Scand F Soc Med 1987; 15: $233-40$ 